\title{
Promoting Student Teachers' Self-Regulated Learning in the Workplace
}

\author{
Emmy Vrieling-Teunter ${ }^{1}$ (D) . Sjef Stijnen ${ }^{1} \cdot$ Theo Bastiaens $^{1}$
}

Received: 18 March 2020 / Accepted: 26 January 2021 / Published online: 8 February 2021

(c) The Author(s) 2021

\begin{abstract}
This quasi-experimental study of self-regulated learning (SRL) in the context of primary teacher education emerged from the importance attributed to SRL for developing student teachers' active and conscious learning. Contrary to earlier studies that focused on SRL within the initial teacher training, in this study we sought for the impact of increased SRL opportunities on student teachers' motivation for learning in their workplace which is an important part of their educational program. The study focused on the way in which SRL opportunities for student teachers can be shaped in the workplace (research question one), the differences in perceived SRL opportunities between the experimental and the control condition (research question two) and the differences in motivation for learning between the experimental and the control condition (research question three). In answer to research question one, the earlier findings of SRL within the initial teacher program were combined with the insights and experiences of the stakeholders in practice. This resulted in a SRL approach for the workplace that was applied during one academic year by 12 primary teacher educators in cooperation with 45 primary teachers of 45 training schools. In answer to research question two, the training appeared effective because student teachers in training schools $(\mathrm{N}=80)$ experienced more SRL opportunities than student teachers in the non-training schools $(\mathrm{N}=51)$. In answer to research question three, student teachers in training schools demonstrated more motivational expectancy (i.e. control belief and self-efficacy for learning) compared with student teachers in non-training schools. This was in line with previous findings within initial teacher training. The importance of a gradual transition from teacher control to student control appeared vital.
\end{abstract}

Keywords Self-regulated learning · Motivation · Teacher education · Workplace learning

Emmy Vrieling-Teunter

emmy.vrieling@ou.nl

1 Faculty of Educational Sciences, Open Universiteit, Valkenburgerweg 177, 6419 AT Heerlen, the Netherlands 


\section{Introduction}

This quasi-experimental study starts from the importance of self-regulated learning (SRL) for students' academic performance. When students possess SRL skills, they can actively engage in constructing their own understanding, being of great value to their learning (Power 2016). Because of the promising consequences of SRL, teacher educators are encouraged to facilitate students' SRL in teacher training programs (Vrieling-Teunter et al. 2018). However, teacher educators often find it difficult to actually foster SRL in educational programs (Korthagen et al. 2000). Therefore, previous studies have focused on facilitating students' SRL throughout teacher education (Vrieling-Teunter et al. 2012a, b). However, these studies were limited to initial teacher education and did not include students' workplace. Therefore, the present study searches for ways to shape SRL opportunities in the workplace being an essential component of students' educational training. To investigate whether the workplace approach is effective, we follow students in training and non-training schools and look for the differences in perceived SRL opportunities. Because students' use of SRL skills in teacher training programs can result in increased motivational beliefs or attitudes (Bruinsma 2004), also being of importance for students' academic performance (Vrieling-Teunter et al. 2018), the differences in motivation for learning between the two conditions are investigated as well. This introduction section first defines SRL and describes how SRL can be attributed to the academic performance of students. Second, guidelines for SRL are elaborated that have proven useful in the initial pre-service teacher curriculum. Subsequently, the importance of SRL for students' motivation for learning is elaborated. Finally, the problem definition with corresponding research questions is formulated.

\section{Importance of Self-Regulated Learning}

Self-regulated learning (SRL) can be defined as a goal-oriented process in which students, from a 'forethought phase', monitor, control and evaluate their own learning (Pintrich 2004). Many studies (e.g. Sundre and Kitsantas 2004) have shown the importance of acquiring SRL skills for successful learning. SRL is expected to lead to better study results, because students can steer and regulate their learning more consciously (e.g. Nota et al. 2004). Ultimately, the student will then be better able to use the knowledge gained in different situations (i.e. transfer). Besides the SRL phases, the four areas for regulation include a) cognition (e.g., knowledge activation, knowledge of strategies), b) motivation and affect (e.g., achievement goals, achievement attributions, self-efficacy), c) behavior (e.g., time, effort), and d) context (resources, social context). In such approaches of SRL, the cognitions, motivations and learning of individuals cannot be comprehended unless social and cultural context, such as support from teachers and feedback from peers, are taken into consideration (Järvelä et al. 2008).

Due to the positive effects of SRL on academic performance, primary teacher educators (from now on teacher educators) are increasingly being encouraged by policy makers to implement SRL in the educational program. For teacher educators 
this means that, in addition to the traditional role of knowledge providers, they will have a more prominent role as supervisors of the student teachers' (from now on students) learning process (Degago and Kaino 2015). In this way, students can become adaptive learners and employees, preparing them for lifelong learning (Gallego-Arrufat and Gutiérrez-Santiuste 2015). In practice, however, it is often difficult to implement SRL effectively within curricula (Lunenberg and Korthagen 2005). Many teacher educators are not well prepared for embedding SRL in their lessons (Korthagen et al. 2000) and are concerned about the declining value of knowledge transfer (Kremer-Hayon and Tillema 1999). So, the professional development of teacher educators is a point of attention for a successful implementation of SRL in educational programs.

\section{Guidelines for Self-Regulated Learning}

From this constraint, Vrieling-Teunter et al. (2010) described a set of seven guidelines that are important for the introduction of SRL within teacher education curricula. Vrieling-Teunter et al. (2010) call these guidelines SRL opportunities, which can be seen as opportunities to facilitate SRL throughout students' training. The SRL guidelines are intended for both initial training and the workplace. After all, it is not only within the initial teacher training that students are required to manage their own learning. Also in the workplace, they are expected to formulate their own goals, include these goals in a personal development plan, prepare lessons and show their development in a portfolio (Vrieling-Teunter et al. 2018). In general, the guidelines are developed from a metacognitive perspective (area cognition, see "Introduction" section) that plays an important role in SRL (e.g. Muis and Franco 2010). It represents students' awareness of academic strengths and weaknesses, cognitive sources that can be used to meet the requirements of specific learning tasks, and their knowledge of how to regulate their involvement in the learning tasks in order to optimize learning processes and results. Besides metacognition, the area of behavior is integrated in the approach, because working on metacognition automatically influences students' behavior. Furthermore, the area of context is taken into account in the form of collaboration. This also means that the area of motivation is dealt with less prominently in the approach (Vrieling-Teunter et al. 2018).

The first set of guidelines concerns the importance of a sufficient knowledge base for students in the domain (subject area). Teacher educators are the experts in their field and it is their task to make this domain accessible to students (e.g. Bolhuis and Voeten 2001). The second set of guidelines underlines the importance of facilitating this knowledge base by integrating the necessary metacognitive skills and subject-specific content during the lessons (e.g. Vermunt and Vermetten 2004). The third set of guidelines states that it is important to model these metacognitive skills (e.g. Schunk and Zimmerman 2007) by making use of four levels, namely observation (looking at an experts' example), emulation (supervised imitation of the example given by an expert), self-control (showing the skills independently within a structured environment) and self-regulation (the adaptive use of the skill in different situations). The fourth set of guidelines emphasizes that it is important to 
gradually develop from teacher guidance to student guidance within learning processes (scaffolding) so that students have a sufficient knowledge base to be able to steer their own learning (e.g. Salonen et al. 2005). The fifth set of guidelines focuses on the importance of raising awareness of the conditional factors that can hinder or strengthen the development of SRL (e.g. Könings et al. 2007): well-prepared teacher educators and students, adequate learning materials that fit in with SRL (including the learning task, see guide seven) and a culture in the school that encourages SRL. The sixth guideline concerns the importance of focusing on involving students in collaborative learning environments (e.g. Wigfield et al. 2007). This cooperation can be promoted by ensuring positive interdependence, clear cooperation instructions and targeted feedback on the cooperation process of students (e.g. Bolhuis and Voeten 2001).

Finally, the seventh guideline focuses on the importance of including relevant SRL aspects in the learning task (e.g. Vrieling-Teunter et al. 2018), namely setting goals (students learn to set their own learning goals and activities for the lesson), prior knowledge activation (responding to what students already know), metacognitive knowledge activation (responding during the 'forethought phase' to learning skills that students need for the performance of the learning task), metacognitive awareness and monitoring of cognition (encouraging students to think about their own learning), judgements (making students aware of their own judgment and possible other perspectives, e.g. peer feedback), attributions (offering students leads to improve their own actions), task value activation (letting students experience what they need a certain learning task for) and time management (teaching students how to organize their time, so that they can arrange their own learning process).

\section{Self-Regulated Learning and Motivation for Learning}

The SRL guidelines have been tested within the initial teacher training by Vrieling-Teunter et al. (2012a, b). The results show that teacher educators were able to increase students' SRL opportunities in the educational program. The studies of Vrieling-Teunter et al. (2012a, b) also looked for students' motivation for learning as an outcome, because earlier studies demonstrated that students who display more adaptive SRL strategies show higher motivational beliefs or attitudes that are also important ingredients for students' academic performance (Bruinsma 2004; Pintrich 2000, 2004; Vrieling-Teunter et al. 2018). Students' motivation for learning, referring to 'a student's willingness to engage in and persist in a task' (Wolters 2003, p. 190), was enhanced during one semester in learning environments with increased SRL opportunities, but this increase appeared not to be significant. However, students' expectancy, a sub-scale within motivation, increased significantly after the implementation of SRL opportunities in students' learning. The expectancy scale includes control belief and self-efficacy for learning, e.g. 'I believe I will receive an excellent grade in this class' (Pintrich et al. 1991). In more detail, control belief stands for the perception that students have internal control over their own learning and effort; self-efficacy for learning indicates students' judgments of their capability to do their work (Pintrich 2004). Students appreciated the increase in SRL because 
their active conscious role gave them more belief in their capability to complete the study assignments, the tests and the transfer between the theory of the program and their own class practice (Vrieling-Teunter et al. 2012a, b). This is important because students often find it difficult to apply the acquired knowledge in the daily practice of the class (Korthagen et al. 2000).

\section{Problem Definition and Research Questions}

Although the SRL guidelines are intended for both initial training and the workplace, until now we have only tested the guidelines within the initial teacher training to facilitate SRL of students. Therefore, in the present study, the SRL guidelines are made practice ready for the workplace to be used as an intervention. This leaves us to the first research question on how SRL can be shaped in the workplace of students with the help of the SRL guidelines as described in "Importance of Self-Regulated Learning" section. In this way, the earlier research results of Vrieling-Teunter et al. (2010), which exclusively relate to SRL within the initial teacher training, are linked to important elements of learning in the workplace, resulting in a workplace approach for SRL. Subsequently, it will be investigated whether there are differences between the SRL opportunities experienced by the students in an experimental condition (workplace approach followed for SRL, see "Participants" section) and a control condition (research question 2). Finally, it will be investigated to what extent there are differences in motivation for learning between students in the experimental and control condition (research question 3).

Summarizing the research questions:

1) How can SRL opportunities for students in the workplace be shaped?

2) What are the differences in perceived SRL opportunities between the experimental and the control condition?

3) What are the differences in motivation for learning between the experimental and the control condition?

This article continues with a description of the methods used, containing an explanation of the design, participants, interventions, and data analysis. Then, the results of the study are outlined and conclusions for teacher education are discussed, including the limitations of the study and indications for future research.

\section{Method}

\section{Design of the Study}

In order to answer the research questions of the present study, a quasi-experimental study was conducted using a mixed methods control group design. Table 1 visualizes the research design of the present study. Students' SRL opportunities and motivation for learning were quantitatively measured with respectively the 'SRL 
Table 1 Design of the study

\begin{tabular}{|c|c|c|c|c|c|c|c|c|c|c|}
\hline Months & 1 & 2 & 3 & 4 & 5 & 6 & 7 & 8 & 9 & 10 \\
\hline \multicolumn{11}{|l|}{ Data collection: } \\
\hline -SRLOQ-W (S) & & & & & & & & & $\mathrm{x}$ & \\
\hline -MVQ (S) & & & & & & & & & $\mathrm{x}$ & \\
\hline -Monitoring questionnaire (TE/T) & & & & & $\mathrm{x}$ & & & & & \\
\hline -Focus group (S) & & & & & & & & $\mathrm{x}$ & & \\
\hline -Interviews (S) & & & & & & & & $\mathrm{x}$ & $\mathrm{x}$ & \\
\hline -Peer review meetings (S/TE/T) & & $\mathrm{x}$ & $\mathrm{x}$ & & $\mathrm{x}$ & $\mathrm{x}$ & & $\mathrm{x}$ & $\mathrm{x}$ & \\
\hline \multicolumn{11}{|l|}{ Interventions: } \\
\hline -Consultations (TE/T) & $\mathrm{x}$ & $\mathrm{x}$ & $\mathrm{x}$ & $\mathrm{x}$ & $\mathrm{x}$ & $\mathrm{x}$ & $\mathrm{x}$ & $\mathrm{x}$ & $\mathrm{x}$ & $\mathrm{x}$ \\
\hline -Study days (TE/T) & & $\mathrm{x}$ & & & $\mathrm{x}$ & & $\mathrm{x}$ & & & $\mathrm{x}$ \\
\hline
\end{tabular}

Opportunities Questionnaire for the workplace' (SRLOQ-W, see "Self-Regulated Learning Opportunities Questionnaire for the Workplace" section) and the "Motivation Questionnaire' (MVQ, see "Motivation Questionnaire" section). The SRLOQ$\mathrm{W}$ and the MVQ were performed at the end of the research period (month 9), since at that time students had gained experience in learning. Teacher educators and primary teachers (from now on teachers) were qualitatively tracked (see "Qualitative Instruments" section) by the 'Monitoring Questionnaire' (month 5). Students were qualitative monitored by a focus group (month 8 ), and retrospective semi-structured interviews (months 8 and 9). The focus group and the interviews were held before the workplace assessments of the students and audio recorded. In addition, audio files of the peer review meetings (see "Qualitative Instruments" section) were collected (months 2-3, 5-6, 8-9). The meetings of the focus group, interviews and peer review meetings were audio recorded using voice recorders and transcribed. Table 1 shows in parentheses whether the data was collected from students $(\mathrm{S})$, teacher educators (TE), or teachers (T).

Besides data collection, two kinds of interventions were carried out with teacher educators and teachers aimed at increasing students' SRL opportunities in the workplace: ten monthly consultations with a small development group consisting of three teacher educators, one teacher, two managers from the initial teacher training and two researchers, and four study days with all participating teacher educators and teachers (see "Participants" section). The guidelines for SRL (see "Guidelines for Self-Regulated Learning" section) formed the basis of the interventions. During the research period, the teacher educators and teachers involved worked on increasing students' SRL opportunities in the workplace (see "Participants" section). The students they supervised in the workplace, formed the experimental group (see "Participants" section).

\section{Participants}

In this study, 12 teacher educators and 45 teachers from 45 training schools (experimental condition) took part during one academic year (10 months). The workplace 
teachers of students in the control group (non-training schools) did not participate in the study. In total, 131 (30 males and 101 females) first- $(\mathrm{N}=62)$ and secondyear $(\mathrm{N}=69)$ students (mainly $17-23$ years old; mean age 19.60 years) participated. Students' former level of education comprised lower general, followed by senior secondary education (low level, $\mathrm{N}=57$ ), higher general secondary education (middle level, $\mathrm{N}=72$ ), and pre-university education (high level, $\mathrm{N}=2$ ). From the primary schools where the teachers were trained in encouraging SRL among the students (see "Design of the Study" section), 80 students participated in the experimental group. The other 51 students formed the control group. The two groups were relatively similar in terms of their age, gender and level of education.

\section{Instruments}

\section{Self-Regulated Learning Opportunities Questionnaire for the Workplace}

For this study, the 'Self-Regulated Learning Opportunities Questionnaire' (SRLOQ; Vrieling-Teunter et al. 2013) was further developed as a tool for the workplace (SRLOQWorkplace or SRLOQ-W). The SRLOQ is a self-report instrument designed to assess students' SRL opportunities in classroom practice. It contains 56 items, divided in five scales: planning (17 items), monitoring (6 items), zone of proximal development (12 items), coaching/judging (16 items) and collaboration (5 items). Except for the items concerning the manual that ask for a yes or no reply, the items are scored on a five-point Likert scale. For the purpose of developing the SRLOQ-W, two phases were completed, namely (1) the qualitative phase of the adapted formulation of the items for use in the workplace, including shortening of the instrument and (2) the phase of the quantitative analysis.

In the qualitative phase, all 13 items relating to the electronic learning environment (e.g. for the planning scale: 'The electronic learning environment describes how this course can support me in my development towards primary teacher') were first removed from the questionnaire since the learning environment was not used by the students and their supervisors in the workplace. Second, the remaining 43 items of the SRLOQ were rewritten into a suitable formulation for the workplace (e.g. for the planning phase 'The teacher expects me to describe personal learning goals for this course' was altered into 'In the workplace the teacher expects me to describe my personal learning goals'). Third, the instrument was discussed in the development group (see "Design of the Study" section) and shortened by removing all questions that were not related to the workplace (e.g. for the monitoring scale 'The teacher expects me to describe the adjustments of my work after getting feedback for this course'). This led to an instrument with 28 items distributed over the scales of planning (6 items), monitoring (3 items), zone of proximal development (4 items), coaching/judging (11 items) and collaboration (4 items), to be scored on a five-point scale (totally disagree-totally agree). Finally, the SRLOQ-W was discussed with 25 teachers who participated in the intervention (see "Design of the Study" section). We also asked two students who were not part of the respondents to participate. On 
the basis of this discussion, no substantive changes were made to the SRLOQ-W, but the formulation of some items was adapted for clarification.

For the quantitative analysis phase, the SRLOQ-W was filled in by the students involved in this study (see "Design of the Study" section). Then, the dimensional structure of the SRLOQ-W wastested with a confirmatory factor analysis (CFA, Jamovi Statististics 1.2). In line with the five scales of the SRLOQ, the CFA of the SRLOQ-W showed five scales (see Table 2, column 1). The scales 'planning', 'monitoring' and 'collaboration' were conceptually comparable. Differences were visible on the original scales 'zone of proximal development' and 'coaching/judging'. Because the original 'coaching/judging' scale of the SRLOQ showed two conceptually different scales in the SRLOQ-W, it was divided into two separate scales 'coaching' and 'judging'. In this respect, the 'coaching' scale specifically aimed at coaching by the supervisor, of which the original 'zone of proximal development' scale is part. Similar to the scales 'planning', 'monitoring' and 'collaboration', the scale 'judging' explicitly focused on SRL by the student. Based on modification indices provided by Jamovi and based on item content, a number of items had to be removed in order to arrive at a suitable model. This resulted into an instrument with 18 items distributed over the scales of planning (4 items), monitoring (3 items), coaching (4 items), judging (3 items) and collaboration (3 items). Table 2 (column 1) shows the five scales of the SRLOQ-W, the number of items per scale (column 2) and an example item of the SRLOQ-W (column 3).

In addition to the chi-square $\left(\chi^{2}\right)$ statistic, which is an 'exact fit index', the overall fit of the SRLOQ-W was evaluated in the CFA by examining three other types of fit indices as suggested by $\mathrm{Hu}$ and Bentler (1998). The Root Mean Square Error of Approximation (RMSEA) represents the 'approximate fit indices'. The TuckerLewis Index (TLI) and the Comparative Fit Index (CFI) represent the 'incremental

Table 2 SRL Opportunities Questionnaire for the Workplace (SRLOQ-W)

\begin{tabular}{|c|c|c|c|}
\hline Scales & $\begin{array}{l}\text { Number of } \\
\text { items }\end{array}$ & Item examples & Cronbach's Alpha \\
\hline 1. Planning & 4 & $\begin{array}{l}\text { In the workplace the teacher expects me to } \\
\text { describe my personal learning goals specific, } \\
\text { measurable, acceptable, realistic and time } \\
\text { processing (SMART) }\end{array}$ & $(\alpha=0.72)$ \\
\hline 2. Monitoring & 3 & $\begin{array}{l}\text { In the workplace the teacher expects me to point } \\
\text { out in which areas I need feedback }\end{array}$ & $(\alpha=0.66)$ \\
\hline 3. Coaching & 4 & $\begin{array}{l}\text { In the workplace the teacher provides feedback } \\
\text { on interim products that is based on previously } \\
\text { formulated criteria }\end{array}$ & $(\alpha=0.82)$ \\
\hline 4. Judging & 3 & $\begin{array}{l}\text { In the workplace the teacher expects me to grade } \\
\text { my progress based on previously formulated } \\
\text { criteria }\end{array}$ & $(\alpha=0.89)$ \\
\hline 5. Collaboration & 3 & $\begin{array}{l}\text { In the workplace the teacher expects me to } \\
\text { describe the way I collaborate with peers }\end{array}$ & $(\alpha=0.85)$ \\
\hline
\end{tabular}


Table 3 Model fit indices

\begin{tabular}{lllllll}
\hline Model & $\chi^{2}$ & df & RMSEA & TLI & CFI & SRMR \\
\hline SRLOQ-W & $153^{*}$ & 109 & 0.0552 & 0.946 & 0.957 & 0.0582 \\
\hline
\end{tabular}

* significance: $p<0.01$

fit indices', and the Standardized Root Mean Square Residual (SRMR) represents the 'residual based fit indices'. The results are outlined in Table 3.

Because the chi-square $\left(\chi^{2}\right)$ test is highly susceptible to the impact of the sample size (Russell 2002), the $\chi^{2}$ ratio to its degrees of freedom (df) was evaluated instead. Values below 5 for the $\chi^{2} / \mathrm{df}$ (Kline 2005) and values below 0.08 for RMSEA indicate an acceptable fit (Marsh et al. 2004). Values for the TLI and CFI above 0.90 indicate a good fit (Russell 2002), while a SRMR below 0.10 indicate a good fit (Kline 2005). The results for the SRLOQ-W were $\chi^{2} / \mathrm{df}=1.404$, RMSEA $=0.0552$, $\mathrm{TLI}=0.946, \mathrm{CFI}=0.957$, and $\mathrm{SRMR}=0.0582$, which indicates a good fit. In general, the results of the CFA confirmed the five dimensional structure of the SRLOQ$\mathrm{W}$ to be acceptable. Finally, reliability analyses at scale level (see Table 2, column 4) show that the items within the five SRL scales show reasonable ( 0.66 for monitoring) to good (0.89 for judging) coherence.

\section{Motivation Questionnaire}

In order to measure the motivation for learning of students in the workplace, the motivation section of the 'Motivation and Metacognition Questionnaire' (MMQ, Vrieling-Teunter et al. 2012a) was used. This questionnaire is based on the 'Motivated Strategies for Learning Questionnaire' (MSLQ; Pintrich et al. 1991) and has been adapted and validated by Vrieling-Teunter et al. (2012a) for use within primary teacher education. The motivation section of the MMQ contains seven scales,

Table 4 Motivation Questionnaire (MVQ)

\begin{tabular}{|c|c|c|c|}
\hline Scales & $\begin{array}{l}\text { Number of } \\
\text { items }\end{array}$ & Cronbach's Alpha & Item examples \\
\hline $\begin{array}{l}\text { Intrinsic goal } \\
\text { orientation }\end{array}$ & 3 & $\alpha=0.64$ & $\begin{array}{l}\text { I prefer a challenging workplace, even if it is } \\
\text { difficult to learn }\end{array}$ \\
\hline $\begin{array}{l}\text { Extrinsic goal } \\
\text { orientation }\end{array}$ & 6 & $\alpha=0.72$ & $\begin{array}{l}\text { In the workplace, I want to do better than the } \\
\text { average student }\end{array}$ \\
\hline $\begin{array}{l}\text { Intrinsic goal } \\
\text { avoidance }\end{array}$ & 3 & $\alpha=0.63$ & $\begin{array}{l}\text { I worry about not getting the full benefit out } \\
\text { of the workplace }\end{array}$ \\
\hline $\begin{array}{l}\text { Extrinsic goal } \\
\text { avoidance }\end{array}$ & 2 & $\alpha=0.81$ & $\begin{array}{l}\text { I just want to avoid doing poorly in the } \\
\text { workplace }\end{array}$ \\
\hline Task value & 4 & $\alpha=0.76$ & $\begin{array}{l}\text { It is important for me to understand the } \\
\text { workplace experiences }\end{array}$ \\
\hline Expectancy & 8 & $\alpha=0.86$ & $\begin{array}{l}\text { I think that I will get good grades for the } \\
\text { workplace assignments }\end{array}$ \\
\hline Test anxiety & 5 & $\alpha=0.86$ & $\begin{array}{l}\text { In the workplace, I suffer from nerves when } \\
\text { I take a test }\end{array}$ \\
\hline
\end{tabular}


namely intrinsic goal orientation, extrinsic goal orientation, intrinsic goal avoidance, extrinsic goal avoidance, task value, expectancy and test anxiety (see Table 4, column 1). For the present study, the original items of the motivation section of the MMQ (from now on MVQ) were maintained, except for changing the 'course' formulation into a 'workplace' formulation. For example, the item 'I prefer challenging course material, even if it is difficult to learn' was altered into 'I prefer a challenging workplace, even if it is difficult to learn' (see Table 4, column 4). Subsequently, the MVQ was filled in by the students involved in this study (see Participants" section), followed by a reliability analysis. The reliability analysis at scale level led to the removal of one item from the extrinsic goal orientation scale ('I would like the student results to be visible to everyone so I can see how well I score') resulting in a better reliability of the scale. Inquiries with students indicated that this item was not applicable and also not ethical within the educational program. Also, one item of the extrinsic goal avoidance scale ('My concern to perform badly is what motivates me in the workplace') was removed, leading to a better reliability of the scale. Inquiries with students indicated that this item did not apply to the workplace because learning in the workplace is in general primarily something students look forward to. The items within the seven motivation scales show reasonable ( 0.63 for intrinsic goal avoidance) to good ( 0.86 for test anxiety and expectancy) coherence (see Table 4, column 4). The MVQ consists of 31 items (see Table 4, column 2) that are answered on a 5 point Likert scale.

\section{Qualitative Instruments}

The Monitoring Questionnaire was used to gain qualitative insight into the way in which teacher educators and teachers implemented the opportunities of SRL during the academic year (research question 1). It concerned a short questionnaire with three open questions that were answered in writing: (1) which SRL opportunities have you implemented? (2) what is going well? (3) what can be improved? Filling in the questionnaire took approximately ten minutes.

To gain qualitative insight into the experiences of students, a focus group and semistructured interviews were organised face to face. Both the focus group and interviews took approximately 45 min per meeting. In general, the questioning was grounded on (1) the five scales of the SRLOQ-W (planning, monitoring, coaching, judging, collaboration; see "Self-Regulated Learning Opportunities Questionnaire for the Workplace" section), the four phases of modelling (observation, emulation, self-control, self-regulation; see "Design of the Study" section), scaffolding (see "Guidelines for Self-Regulated Learning" section), conditions (see "Guidelines for Self-Regulated Learning" section) and motivation (intrinsic goal orientation, extrinsic goal orientation, intrinsic goal avoidance, extrinsic goal avoidance, task value, expectancy, test anxiety; see "Motivation Questionnaire" section). To investigate the differences between the SRL experiences of students from both conditions, the focus group was organized with four students (two students from the experimental and two students from the control condition). During this meeting, the following topics were discussed: (1) experienced forms of support for SRL, (2) effective forms of support for SRL, (3) points for improvement 
for support for SRL, (4) how support for SRL had been phased out, (5) differences between supporting SRL in the initial teacher training and in the workplace, and (6) benefits from SRL in terms of motivation. To go deeper into the experiences of students in the experimental condition, interviews were held with five students from five training schools. The following topics were discussed: (1) experiences with SRL in the workplace, (2) experienced support and effectiveness of support with SRL and (3) perceived effects of SRL on motivation. In addition to the topics, the manual of the focus group and interviews contained a description of the above-mentioned SRL and motivation concepts that could be used for further questions.

As a part of the SRL approach, six peer review meetings (see "SRL in the Workplace" section) of one to two hours were planned in the workplace. These meetings were attended by all students who were currently on work placement, the accompanying teacher educators and the accompanying teachers.

\section{Data Analysis}

To increase the internal validity of the research results, the analysis was based on triangulation of the quantitative (i.e. SRLOQ-W, MVQ) and qualitative data (Monitoring questionnaire, focus group, interviews, peer review meetings). For SRL, the five SRLOQ-W scales (see Table 2, column 1) were included in the analysis of the data. The same goes for the four steps of modelling (see "Guidelines for Self-Regulated Learning" section, third set of SRL guidelines), scaffolding (see "Guidelines for Self-Regulated Learning" section, third set of SRL guidelines), and the SRL conditions (see "Guidelines for Self-Regulated Learning" section, fifth set of SRL guidelines). For motivation, the seven scales of the MVQ (see Table 4, column 1) were included. Table 5 presents the quantitative instruments (column 2), qualitative instruments (column 3) and variables (column 4) used for each research question (column 1). The variables that are presented in column 4 (SRL opportunities, modelling, scaffolding, conditions and motivation) including their sub variables, were integrated in a matrix. Per variable, two researchers independently first analysed the data from all sources using qualitative content analysis (Patton 2015). During this first step, segments and sentences were coded by giving them names and descriptions (e.g. SRL-planning). Second, similarities and differences in the view of the researchers were discussed with a third researcher until agreement was reached. Finally, the results of the analysis were synthesized to identify similarities, differences and patterns, mainly focusing on possible relations between the perceived SRL opportunities and students' motivation for learning. Independent t-tests were used to analyse the quantitative data (SPSS Statistics 24). As can be seen in Table 5, the answering of research question 1 was informed by qualitative data that was collected during the research period at different time points. Research questions 2 and 3 were informed by the quantitative and qualitative data that was gathered at the end of the research period. 
Table 5 Research instruments and variables per research question

\begin{tabular}{|c|c|c|c|}
\hline & $\begin{array}{l}\text { Quantitative } \\
\text { instruments }\end{array}$ & Qualitative instruments & Variables \\
\hline \multirow[t]{4}{*}{ Research question 1} & & $\begin{array}{l}\text {-peer review meetings } \\
\text {-focus group } \\
\text {-interviews } \\
\text {-monitoring questionnaire }\end{array}$ & $\begin{array}{l}\text { SRL opportunities: } \\
\text {-planning } \\
\text {-monitoring } \\
\text {-coaching } \\
\text {-judging } \\
\text {-collaboration }\end{array}$ \\
\hline & & $\begin{array}{l}\text {-peer review meetings } \\
\text {-focus group } \\
\text {-interviews }\end{array}$ & $\begin{array}{l}\text { Modelling: } \\
\text {-observation } \\
\text {-emulation } \\
\text {-self-control } \\
\text {-self-regulation }\end{array}$ \\
\hline & & $\begin{array}{l}\text {-peer review meetings } \\
\text {-focus group } \\
\text {-interviews }\end{array}$ & Scaffolding \\
\hline & & $\begin{array}{l}\text {-peer review meetings } \\
\text {-focus group } \\
\text {-interviews }\end{array}$ & $\begin{array}{l}\text { Conditions: } \\
\text {-student } \\
\text {-teacher } \\
\text {-learning environment } \\
\text {-culture }\end{array}$ \\
\hline Research question 2 & SRLOQ-W & $\begin{array}{l}\text {-focus group } \\
\text {-interviews }\end{array}$ & $\begin{array}{l}\text { SRL opportunities: } \\
\text {-planning } \\
\text {-monitoring } \\
\text {-coaching } \\
\text {-judging } \\
\text {-collaboration }\end{array}$ \\
\hline Research question 3 & MVQ & $\begin{array}{l}\text {-focus group } \\
\text {-interviews }\end{array}$ & $\begin{array}{l}\text { Motivation: } \\
\text {-intrinsic goal orientation } \\
\text {-extrinsic goal orientation } \\
\text {-intrinsic goal avoidance } \\
\text {-extrinsic goal avoidance } \\
\text {-task value } \\
\text {-expectancy } \\
\text {-test anxiety }\end{array}$ \\
\hline
\end{tabular}

\section{Results}

In this section, the quantitative and qualitative findings are presented for SRL ("SRL in the Workplace" section) and motivation ("SRL and Motivation for Learning" section), resulting in the answering of the research questions.

\section{SRL in the Workplace}

In answer to research question 1 (How can SRL opportunities for students in the workplace be shaped?), the qualitative data of the peer review meetings, focus group, interviews and monitoring questionnaire (see Table 5, research question 1 , column 3) were analysed to get a grip on the variables SRL opportunities, modelling, scaffolding and conditions (see Table 5, research question 1, column 4). From 
the analysis, it became clear that the participants were able to use the seven guidelines for SRL (see "Guidelines for Self-Regulated Learning" section) to develop the SRL approach. The final approach focused on three main themes, namely collaborative learning (guideline 6, collaborative learning environments), peer feedback (guideline 7, judging), and a gradual transition from teacher to student directed learning (guideline 4, scaffolding). In order to promote collaborative learning, six peer review meetings of one to two hours were planned in the workplace (see "Qualitative Instruments" section). For the provision of peer feedback as a specific focus within collaboration, monitoring indicators were developed to help students carry out lesson visits. The guidance in SRL (scaffolding) consisted of the preparation and guidance of peer review meetings, lesson visits and related issues such as working with lesson preparation forms and formulation of goals.

During the research period, the direction of students' learning became more and more in the hands of the students (scaffolding). In the peer review meetings (collaboration), attention was paid to planning because the students learned how to formulate their personal goals, in line with the competences that they were expected to develop from the initial teacher training. In the area of monitoring, work was done on learning to ask for and give feedback from the students' own goal formulation. For the peer review meetings, the agenda was increasingly determined by the students (scaffolding). Attention was also paid to collaboration in the form of peer feedback on the basis of lesson visits that students made together. This was done using monitoring indicators that were developed in the peer review meetings under the guidance of the teachers and teacher educators (coaching). The main emphasis was on collaboration between the students. In this matter, it was also interesting to note that the first-year students were involved by second-year students when they needed help with their assignments (e.g. needing a helping hand in data collection). Although students provided peer feedback with a focus on tips and tops, judging each other's progress was not part of learning in the workplace.

In addition, it became clear that it would be desirable to integrate peer review meetings more closely within the initial teacher training. It is important for the students that SRL skills are gradually given a place within the study program (scaffolding). Modelling is important here. Within the program, skills such as goal formulation, lesson preparation and peer feedback were offered (phase of observation), but not always practised with assistance (phase of emulation). In such a procedure, students are expected to immediately start working with the acquired skill (phase of self-control) in the workplace, while in fact they are not yet able to do so (insufficient knowledge base). In the area of the conditions that can hinder or strengthen the development of SRL, it turned out that the electronic learning environment was too static for students to show the progress in a way that was appropriate for them.

In answer to research question 2 (What are the differences in perceived SRL opportunities between the experimental and the control conditions?), an analysis was made of whether there were visible differences between the perceived SRL opportunities of the students in both conditions. First, based on an independent t-test, it was examined whether there were differences between the SRL opportunities (measured with the SRLOQ-W) of the students in the experimental group and the control group at the end of the research period. In Table 6, the five SRL scales (planning, 
Table 6 Results of the independent t-test for SRL opportunities in the workplace

\begin{tabular}{llllllll}
\hline Scale & Groups & $M$ & $S D$ & $t$ & $d f$ & $P$ & Cohen's $d$ \\
\hline Planning & Experimental & 16.48 & 2.05 & 2.98 & 129 & $0.003^{*}$ & 0.54 \\
& Control & 15.27 & 2.52 & & & & \\
Monitoring & Experimental & 11.34 & 1.65 & 2.39 & 129 & $0.018^{* *}$ & 0.43 \\
& Control & 10.59 & 1.90 & & & & \\
Coaching & Experimental & 16.03 & 1.80 & 1.89 & 129 & $0.000^{*}$ & 0.70 \\
& Control & 14.34 & 2.58 & & & & 0.49 \\
Judging & Experimental & 11.74 & 1.82 & 3.52 & 76.32 & $0.001^{*}$ & 0.92 \\
& Control & 10.71 & 2.51 & & & & \\
Collaboration & Experimental & 10.18 & 1.87 & 4.70 & 76.46 & $0.000^{*}$ & 0.92 \\
& Control & 8.02 & 2.92 & & & & \\
\hline
\end{tabular}

${ }^{*} p<0.01$

${ }^{* * *} p<0.05$

monitoring, coaching, judging, collaboration) of the students from the experimental group and the control group are presented.

The results show that the average values of the five SRL scales of the experimental group are higher than the average values of the control group. This difference is significant at the 0.01 significance level with medium to large effects for four scales (planning, coaching, judging, collaboration) and significant at the 0.05 significance level with a medium effect for one scale (monitoring). Overall, this shows that students in the experimental condition experienced more SRL opportunities on the five SRL scales than students in the control condition. The qualitative data showed that the perceptions of the teachers, teacher educators and the students about the SRL opportunities obtained were in line with each other. However, the teachers and teacher educators already looked at their educational activities with a more critical eye than the students who perceived the activating method as a new and 'different way of working' compared to previous experiences in the workplace.

\section{SRL and Motivation for Learning}

In answer to research question 3 (What are the differences in motivation for learning between the experimental and the control condition?), an independent t-test was used to determine whether differences were visible between the motivation for learning of the students in the experimental group and the control group at the end of the research period (see Table 7). Of the seven underlying scales within study motivation, only the sub-scale expectancy differed significantly $\mathrm{t}(93.63)=1.81$,

Table 7 Results of the independent t-test for motivation for learning

\begin{tabular}{llllllll}
\hline Scale & Groups & $\mathrm{M}$ & $\mathrm{SD}$ & $\mathrm{t}$ & $\mathrm{df}$ & $\mathrm{P}$ & Cohen's d \\
\hline Expectancy & Experimental & 31.42 & 3.31 & 1.81 & 93.63 & $0.037 *$ & 0.41 \\
& Control & 30.19 & 4.06 & & & & \\
\hline
\end{tabular}

${ }^{*} p<0.05$ 
$\mathrm{p}<0.05$ between the experimental group $(\mathrm{M}=31.42, \mathrm{SD}=3,31)$ and the control group $(M=30.19, \mathrm{SD}=4.06)$ with a medium effect (Cohen's $\mathrm{d}=0.41)$. The qualitative findings support the differences found between the two groups in terms of expectancy. From the triangulation of the data, we explicitly noticed a pattern in the area of relations between perceived SRL opportunities and expectancy (control belief and self-efficacy for learning; see "Self-Regulated Learning and Motivation for Learning" section). Therefore, we will elaborate on this in more detail.

Through their active role in peer review meetings (collaboration), students got better knowledge of their own plus and minus points and a better impression of what to expect within the study in the coming years (control belief). Also, students experienced more appreciation and felt more like a colleague than a trainee as a result of the collaborative activities. They found it easier to speak to each other, dared to ask for help more quickly, became less hesitant and had more courage to speak in the group (self-efficacy for learning). An important condition in this respect is an open, safe atmosphere of equality. The students indicated that they would like to see the cooperation between students of different years within the initial teacher training.

Visiting each other's lessons (collaboration) was also experienced as instructive. Students noticed that others encountered the same problems. This recognition led to more self-confidence (self-efficacy for learning). Even outside the planned lesson visits, students would look at each other's lessons and provide each other with feedback. By looking at each other, students became accustomed to being observed. There was also less dependence on a supervisor and more objectivity because more people looked at the students. Because students received more feedback from peers and supervisors during the process (coaching), they gained more confidence in the proper execution of the workplace assessments and the final assessment became less of a snapshot (self-efficacy for learning).

The students observed that aspects such as lesson preparation, goal formulation and the provision of peer feedback can be more thoroughly integrated in the study program (modelling). The supervisors have an important role in the development and students cannot be expected to go into depth immediately or as one student indicated: "Students are quickly satisfied". Often, it appeared necessary for teachers to organize extra meetings in the workplace to help students with activities like goal formulation because students felt insufficiently equipped for the execution of the learning tasks (control belief). The same applies to working with a portfolio that proved to be too much of an instrument for the supervisors rather than for the student. More frequent feedback by supervisors (coaching) was seen as a necessary condition for learning to use the portfolio as a tool for managing one's own learning process (control belief).

\section{Conclusions and Discussion}

This study concerns a deepening of earlier research concerning the design of SRL opportunities for students and the importance of this for their motivation for learning. From a critical perspective, the balance is sought between teacher- and studentcontrolled learning in order to create appreciation for SRL. Whereas previous studies 
(Vrieling-Teunter et al. 2012a, b) focused on investigating behavioural changes of students within the initial teacher training, in the current study the translation has been made to the workplace. As a result of the discussion between teacher educators and teachers, learning in the workplace became more of an extension of the curriculum which was a positive development in the light of the often problematic transfer between theory and practice within teacher education.

In answer to research question 1, this study investigated how SRL opportunities of students can be shaped in the workplace. Proposals were made, tried out and evaluated in various cycles, whereby the SRL guidelines (see "Guidelines for Self-Regulated Learning" section) were useful for the participants. The results show that students in the experimental condition experienced significantly more SRL opportunities than students in the control condition (research question 2). Whereas the SRL activities from previous research in the initial teacher training (VrielingTeunter et al. 2012a, b) mainly concentrated on individual activities, we saw in this research that the initiatives for the implementation of SRL opportunities were mainly deployed by students and supervisors working together in peer review meetings and classroom visits in the workplace. Many teacher training programs endorse the importance of learning to work together with peers as a stimulus for the learning process and as an important preparation for their own social role as a future teacher, but in practice this competence is still difficult to implement in the initial teacher training (Dobber 2012). The method described in this study may inspire supervisors to further embed this competence in the program, both within the initial teacher training and in the workplace.

Because the SRL approach in the workplace has crystallized in the direction of a collective approach, we also see similarities with other research in the field of network learning where teachers work together and discuss practice issues while sharing a similar focus on learning (Littlejohn et al. 2019). The findings from both perspectives (collective SRL approach and networked learning) can be brought together when designing forms of social learning within teacher education. In this matter, we can also draw on research from Panadora and Järvelä (2015) that focuses on socially shared regulation of learning, an interesting angle that is receiving increasing attention (Panadero 2017).

In reaction to research question 3 , this study also investigated which motivational behavioural changes in students became visible after the implementation of SRL opportunities in the workplace. In line with previous research within initial teacher training (Vrieling-Teunter et al. 2012a, b), it became clear that students in workplace learning environments with SRL opportunities seem to experience more expectancy than students in learning environments where such opportunities are less prominent. In this sense, despite the different perspectives on SRL in the two research contexts (individual versus collective), the results in the workplace reinforce the previously found conclusions within the initial teacher training. Because the focus was increasingly on the initiative of the students, for students it gave a better picture of their strengths and weaknesses (control belief). This growth in the area of monitoring one's own learning process led to more confidence for the proper execution of interim assignments (such as the formulation of a personal development plan) and the final assessment in the workplace (self-efficacy for learning). We also saw that by collaborating, students 
became more confident in communicating with (future) colleague teachers An important condition in this respect concerned the ability to collaborate in openness and equality.

The present research also has some limitations. First, the small number of items within the extrinsic goal avoidance scale of the SRLOQ-W is a point of attention. In future research it is recommended to further validate the instrument in different settings. Second, students were followed for a short period of one academic year. It is advisable to monitor students for a longer period than one academic year, so that SRL development and motivational changes may come to the fore more clearly. Third, SRL opportunities and motivation for learning were only measured at the end of the research period. In future research, it is recommended to measure motivation not only at the end, but also at the start of the research period. In this way can be controlled for previous levels of motivation of the participants.

In order to guarantee a gradual SRL implementation, future research can train teachers and teacher educators to use the SRLOQ-W as a diagnostic tool in the workplace. Earlier research within initial teacher training (Vrieling-Teunter et al. 2012a, b) shows that, after training, supervisors can determine which SRL opportunities they already offer to students in the current situation and where the most important opportunities for improvement lie. In addition, a teacher version of the SRLOQ-W can be developed in which the items are formulated from the perspective of the teacher. In this way, the perceptions of both groups can be compared in order to obtain a more objective picture of the perceived SRL opportunities in the workplace.

In the present research, motivation was viewed as a product or state (i.e. an outcome variable of SRL). From this perspective, students have a level of motivation that they experience and that influences their choice, effort and persistence regarding a particular activity (Wolters 2003). When we view motivation as a process which is often the case in SRL studies (Vrieling-Teunter et al. 2018), motivation refers not just to an end state but also to the means through which that state is determined (Wolters 2003). In other words, motivational tendencies change during classroom learning (Järvelä et al. 2008) and students can learn to regulate their motivational status (Wolters 2003). This is in line with the work of Pintrich (2004) that distinguishes motivation as a key factor of SRL that is infused throughout all phases. It is therefore interesting in future research to focus on the broad pallet of SRL and include motivation as an area in the SRL approach. In this sense, it is interesting to monitor some supervisors and their students in depth, for example on the basis of a case study.

The described positive effects of SRL opportunities for students, both in the initial teacher training and in the workplace, indicate the important role of supervisors in the implementation process of SRL. Following the earlier discussion by VrielingTeunter et al. (2018) about the importance of a balance between teacher and student guidance, it becomes clear once again in this study that students in the workplace are only capable of SRL if a number of conditions are met. For a gradual implementation of SRL opportunities in educational curricula, it is important to use the four phases of modelling (observation, emulation, self-control, self-regulation). In this respect, good consultation between teachers and teacher educators is conducive 
to achieve a balanced distribution of the four phases of modelling between the two learning places of students. In this way, a learning situation is created for students in which education and the workplace are no longer seen as separate entities.

\section{Declarations}

Conflict of Interest No potential conflict of interest was reported by the authors.

Open Access This article is licensed under a Creative Commons Attribution 4.0 International License, which permits use, sharing, adaptation, distribution and reproduction in any medium or format, as long as you give appropriate credit to the original author(s) and the source, provide a link to the Creative Commons licence, and indicate if changes were made. The images or other third party material in this article are included in the article's Creative Commons licence, unless indicated otherwise in a credit line to the material. If material is not included in the article's Creative Commons licence and your intended use is not permitted by statutory regulation or exceeds the permitted use, you will need to obtain permission directly from the copyright holder. To view a copy of this licence, visit http://creativecommons.org/licen ses/by/4.0/.

\section{References}

Bolhuis, S., \& Voeten, M. J. M. (2001). Toward self-directed learning in secondary schools: What do teachers do? Teaching and Teacher Education, 17(7), 837-855.

Bruinsma, M. (2004). Motivation, cognitive processing and achievement in higher education. Learning and Instruction, 14(6), 549-568.

Degago, A. T., \& Kaino, L. M. (2015). Towards student-centred conceptions of teaching: The case of four Ethiopian universities. Teaching in Higher Education, 20(5), 493-505.

Dobber, M. (2011). Collaboration in groups during teacher education [Doctoral dissertation, Leiden University]. https://scholarlypublications.universiteitleiden.nl/handle/1887/17720.

Gallego-Arrufat, M.-J., \& Gutiérrez-Santiuste, E. (2015). Perception of democracy in computer-mediated Communication: Participation, responsibility, collaboration, and reflection. Teaching in Higher Education, 20(1), 92-106.

Hu, L.-T., \& Bentler, P. M. (1998). Fit indices in covariance structure modeling: Sensitivity to underparameterized model specification. Psychological Methods, 3(4), 424-453.

Järvelä, S., Järvenoja, H. B., \& Veermans, M. (2008). Understanding the dynamics of motivation in socially shared learning. International Journal of Educational Research, 47(2), 122-135.

Kline, R. B. (2005). Principles and practice of structural equation modeling (2nd ed.). New York: Guilford.

Könings, K. D., Brand-Gruwel, S., \& van Merriënboer, J. G. (2007). Teachers' perspectives on innovations: Implications for educational design. Teaching and Teacher Education, 23(6), 985-997.

Korthagen, F., Klaassen, C., \& Russell, T. (2000). New learning in teacher education. In P.R.-J. Simons, J. Van der Linden, \& T. Duffy (Eds.), New learning (pp. 243-259). Dordrecht: Kluwer Academic Publishers.

Kremer-Hayon, L., \& Tillema, H. H. (1999). Self-regulated learning in the context of teacher education. Teaching and Teacher Education, 15, 507-522.

Littlejohn, A., Jaldemark, J., Vrieling-Teunter, E., \& Nijland, F. (2019). Networked professional learning: An introduction. In A. Littlejohn, J. Jaldemark, E. Vrieling-Teunter, \& F. Nijland (Eds.), Networked professional learning: Emerging and equitable discourses for professional development (pp. 1-11). New York: Springer.

Lunenberg, M., \& Korthagen, F. A. J. (2005). Breaking the didactic circle: A study on some aspects of the promotion of student-directed learning by teachers and teacher educators. European Journal of Teacher Education, 28(1), 1-22.

Marsh, H. W., Hau, K., \& Wen, Z. (2004). In search of golden rules: Comment on hypothesis-testing approaches to setting cutoff values for fit indexes and dangers in overgeneralizing Hu and Bentler's (1999) findings. Structural Equation Modeling, 11(3), 320-341. 
Muis, K. R., \& Franco, G. M. (2010). Epistemic profiles and metacognition: Support for the consistency hypothesis. Metacognition and Learning, 5(1), 27-45.

Nota, L., Soresi, S., \& Zimmerman, B. J. (2004). Self-regulation and academic achievement and resilience: A longitudinal study. International Journal of Educational Research, 41, 198-215.

Panadero, E. (2017). A review of self-regulated learning: Six models and four directions for research. Frontiers Psychology, 28(4), 1-28.

Panadora, E., \& Järvelä, S. (2015). Socially shared regulation of learning: A review. European Psychologist, 20(3), 190-203.

Patton, M. Q. (2015). Qualitative Research \& Evaluation Methods (4th ed.). London/New Delhi: SAGE.

Pintrich, P. R. (2000). The role of goal orientation in Self-regulated learning. In M. Boekaerts, P. R. Pintrich, \& M. Zeidner (Eds.), Handbook of Self-Regulation (pp. 451-502). San Diego, CA: Academic Press.

Pintrich, P. R. (2004). A conceptual framework for assessing motivation and self-regulated learning in college students. Educational Psychology Review, 16, 385-407.

Pintrich, P. R., Smith, D., Garcia, T., \& McKeachie, W. J. (1991). A manual for the use of the Motivated Strategies for Learning Questionnaire (MSLQ). Ann Arbor: University of Michigan, School of Education.

Power, J. B. (2016). Has this begun to change the way they think? Moving undergraduate learners' level of reflection from where it is to where it needs to be. Teaching in Higher Education, 21(3), 235-248.

Russell, D. W. (2002). In search of underlying dimensions: The use (and abuse) of factor analysis in Personality and Social Psychology Bulletin. Personality and Social Psychology Bulletin, 28(12), 1629-1646.

Salonen, P., Vauras, M., \& Efklides, A. (2005). Social interaction: What can it tell us about metacognition and coregulation in learning? European Psychologist, 10(3), 199-208.

Schunk, D. H., \& Zimmerman, B. (2007). Influencing children's self-efficacy and self-regulation of reading and writing through modelling. Reading and Writing Quarterly, 23(1), 7-25.

Sundre, D. L., \& Kitsantas, A. (2004). An exploration of the psychology of the examinee: Can examinee selfregulation and test-taking motivation predict consequential and non-consequential test performance? Contemporary Educational Psychology, 29(1), 6-26.

Vermunt, J. D., \& Vermetten, Y. J. (2004). Patterns in student learning: Relationships between learning strategies, conceptions of learning, and learning orientations. Educational Psychology Review, 16(4), 359-384.

Vrieling-Teunter, E., Bastiaens, T., \& Stijnen, S. (2010). Process-oriented design principles for promoting self-regulated learning in primary teacher education. International Journal of Educational Research, 49(4-5), 141-150.

Vrieling-Teunter, E., Bastiaens, T., \& Stijnen, S. (2012a). Consequences of increased self-regulated learning opportunities on student teachers' motivation and use of metacognitive skills. Australian Journal of Teacher Education, 37(8), 102-117.

Vrieling-Teunter, E., Bastiaens, T., \& Stijnen, S. (2012b). Effects of increased self-regulated learning opportunities on student teachers' metacognitive and motivational development. International Journal of Educational Research, 53, 251-263.

Vrieling-Teunter, E., Bastiaens, T., \& Stijnen, S. (2013). The 'Self-Regulated Learning Opportunities Questionnaire': A diagnostic instrument for primary teacher educators. Professional Development in Education, 39(5), 799-821.

Vrieling-Teunter, E., Stijnen, S., \& Bastiaens, T. (2018). Successful learning: Balancing self-regulation with instructional planning. Teaching in Higher Education, 23(6), 685-700.

Wigfield, A., \& L., Hoa, W., \& Klauda, S.L. (2007). The role of achievement values in the regulation of achievement behaviours. In D. H. Schunk \& B. J. Zimmerman (Eds.), Motivation and self-regulated learning: Theory, research, and applications (pp. 169-195). New York: Lawrence Erlbaum Associates.

Wolters, C. A. (2003). Regulation of motivation: evaluating an underemphasized aspect of self-regulated Learning. Educational Psychologist, 38(4), 189-205.

Publisher's Note Springer Nature remains neutral with regard to jurisdictional claims in published maps and institutional affiliations.

Emmy Vrieling-Teunter is Assistant Professor of Teachers' Professional Development in Social Networks and Self-Regulation at the Open Universiteit, Netherlands. Her research concentrates on exploring social learning dimensions as well as self-regulated learning processes that facilitate professional development in educational institutes. 
Sjef Stijnen is Professor in Distance Education and Teacher Training and Professionalization at the Open Universiteit, Netherlands. His educational research focuses on professional development, feedback, and self-regulated learning of (student)teachers.

Theo Bastiaens is Rector of the Open Universiteit, Netherlands. He is also Professor in educational technology with a research interest in instructional design and e-learning. He has published extensively in this area. 